Journal of Qualitative Criminal Justice \& Criminology

\title{
Welcome to the Journal of Qualitative Criminal Justice \& Criminology (JQCJC)!
}

Willard M. Oliver ${ }^{1}$

${ }^{1}$ Sam Houston State University

Published on: Apr 01, 2013

DOI: $10.21428 / 88 \mathrm{de} 04 \mathrm{a} 1.17944 \mathrm{fa} 1$

License: Creative Commons Attribution 4.0 International License (CC-BY 4.0). 
Criminal Justice and Criminology have a long history of using qualitative methods in the conduct of research, but to date there has been neither a qualitative journal in criminal justice, nor one in criminology. That has now changed with this first issue of the Journal of Qualitative Criminal Justice $\mathcal{E}$ Criminology (JQCJC); and as one leading scholar recently told me, "It's about time!"

What prompted me to launch the new journal is a confluence of various factors including: no qualitative journal outlet in either discipline, a regional journal that had become too "regional," being tired of the rapid expansion of quantitative methods classes in $\mathrm{CJ}$ with not a single qualitative course, having taught the qualitative methods course, having a desire to get in-touch with my qualitative side, the fact that a recent study found from 2004 to 2008 , only $5.74 \%$ of the 2,092 articles published across 13 journals, had used qualitative methods (See Tewksbury, Dabney, \& Copes, 2010), and I simply enjoy reading qualitative research.

All of this led to the creation of the Journal of Qualitative Criminal Justice $\mathcal{E}$ Criminology, the first issue of which you are now reading electronically (or the old fashion way if you just so happened to print it!). JQCJC will publish twice a year, once on April 15, and the second issue on October 15, and it will include what I hope you will agree are some of the top original qualitative research studies, articles on qualitative research methods, qualitative book reviews, and an added feature of one historical book review per issue-high-lighting a seminal qualitative book in CJC.

My role as editor of JQCJC has merely been to serve as a focal point for the qualitative community. Many of the top qualitative scholars in the field are responsible for the product you are now reading. This is evidenced by my fantastic editorial board, which features such leading scholars as Peter Adler, Kathy Charmaz, Dean A. Dabney, Jeff Ferrell, Peter Kraska, J. Mitchell Miller, Mark Pogrebin, and Jock Young. The authors for this issue include scholars such as Heith Copes, Richard Tewksbury, Wilson R. Palacios, Thomas J. Holt, and rising stars such as Allison M. Hicks (trained by Patricia Adler) and Paul M. Klenowski (trained by Kathleen J. Hanrahan). Still further, this issue of JQCJC represents many other leading qualitative scholars in criminal justice and criminology who volunteered their time to conduct the peer-reviews necessary to insure that only the highest quality articles were published in this first issue. My thanks to all of the reviewers, all of whom will be named in the final issue of this first volume. Finally, many of those interested in qualitative research agreed to author book reviews consisting of many of the leading qualitative researchers' recent publications. Among the authors whose works are reviewed include D.K. van den Hoonaard, Kimberly J. Cook, and Geoff K. Ward. I realize there are still many more leading qualitative scholars in the criminal justice and criminology field not mentioned, but please know I truly hope to have you represented in future issues of what I anticipate will become a leading journal in CJC. 
Before I close, I would like to acknowledge several people who have been very supportive of the journal and have worked diligently behind the scenes to make this journal a reality. The first is Heith Copes from the University of Alabama at Birmingham for his highly valued insights. Second are both Patrick Carr (Rutgers University) and Dean A. Dabney (Georgia State University) for their support and guidance and hosting roundtables related to the journal at the annual meetings of The American Society of Criminology and The Academy of Criminal Justice Sciences. Third, I must thank a SHSU doctoral student who is dedicated to qualitative research, Kevin F. Steinmetz, who graciously agreed to take over as book review editor and has done an outstanding job. Finally, I must acknowledge the hard work and dedication of three key people here at Sam Houston State University: my all-time favorite copy-editor Ronda Harris, our webmaster Melina Gilbert, and the go-to person in our publication office Harriet McHale-I could not have done this without the three of you!

In closing I must say, as the editor of the new journal, I hope you find the Journal of Qualitative Criminal Justice \& Criminology to be a significant contribution to CJC, and that you will consider JQCJC as an outlet for your future qualitative research.

\section{References}

Tewksbury, R., Dabney, D.A., \& Copes, H. (2010). The prominence of qualitative research in criminology and criminal justice scholarship. Journal of Criminal Justice Education, 21, 391-411. 